\title{
Bladder outlet resistance decreasing operations in spinal cord damaged patients with vesicoureteral reflux
}

\author{
$\mathrm{H}$ Burgdoerfer MD, ${ }^{1}$ A Bohatyrewicz $\mathrm{MD}^{2}$ \\ ${ }^{1}$ Department of Urology, Paraplegic Centre of the BG-Unfallkrankenhaus, Bergedorfer \\ Strasse 10, 2050 Hamburg 80, West Germany; ${ }^{2}$ Department of Traumatology and \\ Orthopaedy, Pomeranian Medical Academy, Sokolowskiego 11, 70-890 Szczecin, Poland.
}

Bladder outlet resistance decreasing operations were carried out on 68 spinal cord damaged patients with 87 vesicoureteral refluxes in the Paraplegic Centre, Hamburg, from 1982 to 1988. These patients were studied regularly with infusion urography and voiding cystourethrograms combined with urodynamic procedure.

Although the primary aim of the operative treatment was to achieve balanced voiding, $62(71 \%)$ refluxes disappeared, $10(12 \%)$ changed for the better, 13 $(15 \%)$ stood unchanged and $2(2 \%)$ worsened.

It was observed that the results of operative treatment of secondary vesicoureteral reflux depend only on the recuperative capacity of ureterovesical junction after reducing the pathologically increased bladder outlet resistance. Successful treatment of secondary vesicoureteral reflux does not influence renal parenchymal scarring.

In all of the patients with unchanged or worsened reflux balanced voiding has still not been achieved, the bladder outlet resistance being not sufficiently decreased.

Key words: urinary bladder; spinal cord injury; vesicoureteral reflux.

\section{Introduction}

It is evident that vesicoureteral reflux (VUR) in spinal cord (SC) damaged patients is associated with increased bladder outlet resistance and intravesical pressure. ${ }^{1-3}$

It has been observed that VUR occurs more often after inadequate acute urological treatment (acute bladder distension, indwelling catheters, ineffective treatment of urinary tract infections). After acute spinal cord damage we routinely use suprapubic drainage, monitor diuresis and after 2-3 weeks introduce clean intermittent catheterisation.

VUR is discovered by radiological evaluation, and has been reported to be present in $9-25 \%$ of patients after spinal cord injury. ${ }^{4}$ In these patients urodynamic procedures combined with voiding cystourethrograms show unbalanced voiding (Table I) in consequence of increased bladder outlet resistance. ${ }^{5,6}$
In SC damaged patients with unbalanced voiding and VUR, lowering the intravesical pressure is the treatment of choice. ${ }^{5,7}$ Such treatment includes bladder outlet resistance decreasing operations, pharmacotherapy (alpha-adrenergic antagonists, parasympatholytic drugs, prophylaxis and therapy of urinary tract infections), intermittent catheterisation and occasionally, suprapubic drainage. ${ }^{5}$

From 1982 to 1988,1660 spinal cord damaged patients were admitted to the Paraplegic Centre in Hamburg and underwent urological examinations including routine infusion urography and voiding cystourethrograms (under x-ray control before, during and after micturition) combined with urodynamic procedures. One hundred and twelve patients $(6.7 \%)$ were diagnosed as having refluxes: 83 one-sided and 29 bilateral.

This paper describes the fate of 87 VUR in $68 \mathrm{SC}$ damaged patients, who underwent 
Table I Criteria for balanced voiding 5,6

\begin{tabular}{lcc} 
& Balanced & Tolerance limit \\
\hline Compliance & $>25 \mathrm{ml} / \mathrm{cm} \mathrm{H}_{2} \mathrm{O}$ & $15-25 \mathrm{ml} / \mathrm{cm} \mathrm{H}_{2} \mathrm{O}$ \\
Maximal voiding pressure & $<75 \mathrm{~cm} \mathrm{H}_{2} \mathrm{O}$ & $75-100 \mathrm{~cm} \mathrm{H} \mathrm{H}_{2} \mathrm{O}$ \\
Resistance coefficient & $<5 \mathrm{~cm} \mathrm{H} \mathrm{H}_{2} \mathrm{O} / \mathrm{ml} / \mathrm{s}$ & $5-10 \mathrm{~cm} \mathrm{H} \mathrm{H}_{2} \mathrm{O} / \mathrm{ml} / \mathrm{s}$ \\
Residual urine quotient & $0-10 \%$ & $10-20 \%$ \\
Urinary tract infection & - & $1-2$ yearly \\
X-ray: upper urinary tract & without changes & without changes \\
X-ray: lower urinary tract & without changes & without changes \\
\hline
\end{tabular}

transurethral operations to cure an evident functional (rarely anatomical) obstruction at the level of the external sphincter or the bladder neck.

\section{Materials and methods}

Sixty-eight SC damaged patients with VUR are presented: 65 males and 3 females; 63 $(93 \%)$ with traumatic SC lesions. Their ages range from 17 to 72 years with an average age of 28.6 years. The age range (Fig 1) corresponds to that of all patients with SC traumatic lesions treated at the Paraplegic Centre of the BG-Unfallkrankenhaus in Hamburg. The lesion level is mainly in the cervical and thoracic spinal cord (Fig 2), therefore upper motor neuron lesions dominate.

In $5(7 \%)$ of the patients reflux developed as early as within 3 months after the injury, and in $36(53 \%), 3$ years after the injury (Fig 3). Eighteen patients developed bilateral reflux and 50 one-sided, 32 on right and 18 on the left side.

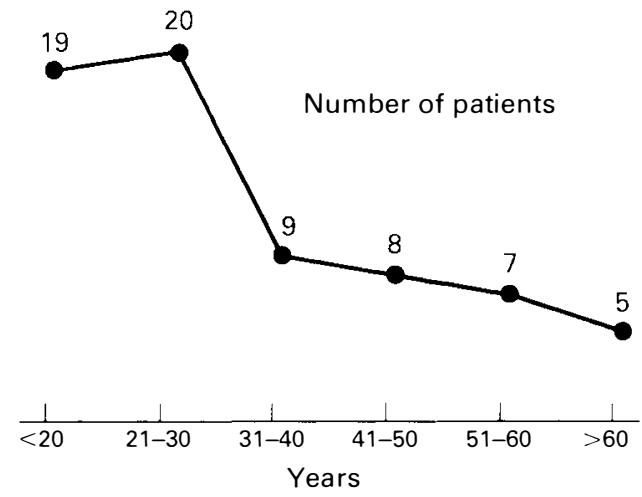

Figure 1 Ages of patients.
We used a modified International Reflux Study Committee criteria to grade the secondary reflux based on the level of retrograde contrast flow during voiding cystourethrogram and the changes in the ureter, renal pelvis and calices. ${ }^{8}$ Grade Ia: the lowest third of ureter only. Grade Ib: lower two-thirds of the ureter. Grade Ic: the ureter up to the pyeloureteral junction. Grade II: the ureter, pelvis and calices; no dilatation. Grade III: mild or moderate dilatation and/or tortuosity of the ureter and mild or moderate dilatation of the renal pelvis. Grade IV: moderate dilatation and/ or tortuosity of the ureter and moderate dilatation of the renal pelvis and calices. Grade V: gross dilatation and tortuosity of the ureter, gross dilatation of the renal pelvis and calices, and papillary impressions no longer visible in most of the calices.

There were 46 refluxes $(53 \%)$ in the ureter only (grade I), and 67 refluxes $(77 \%$ ) with normal caliceal fornices and without dilatation (grade I and II) (Fig 4).

Fifty-three VUR (61\%) were accom-

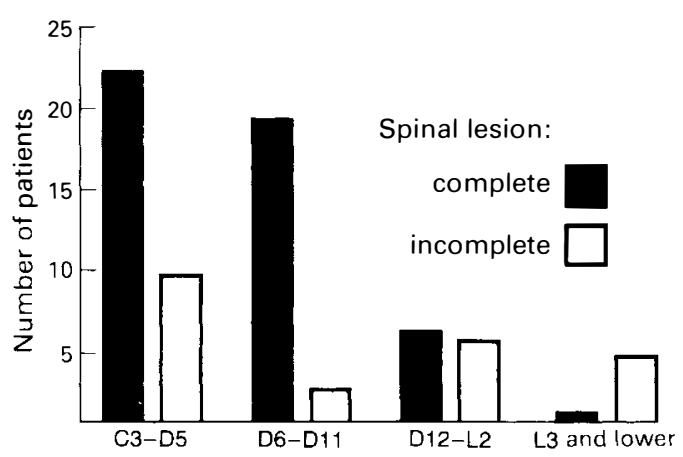

Figure 2 Location of lesion level in the spinal cord. 


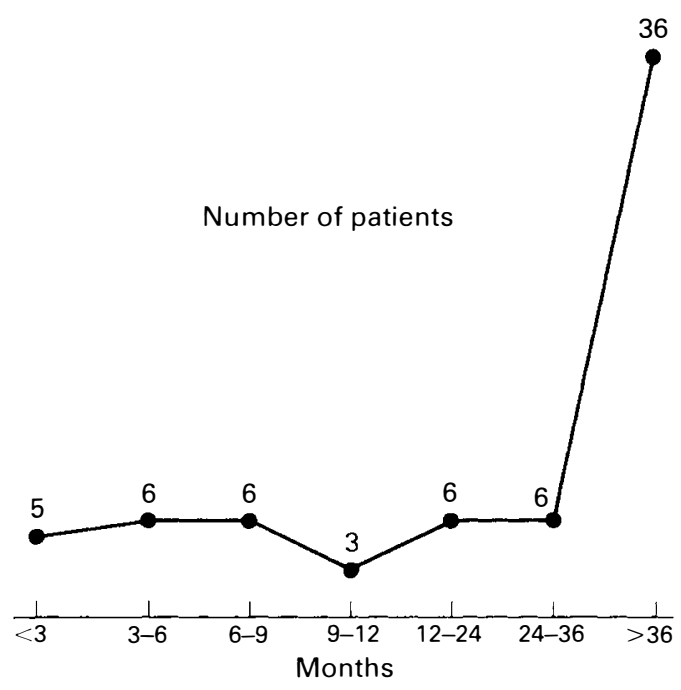

Figure 3 Time from injury to detection of vesicoureteral reflux.

panied by a urinary tract infection detected by leucocyturia and significant bacteriuria $\left(\geqslant 10^{5} / \mathrm{ml}\right)$ and treated with specific antibiotics. To prevent urinary tract infection we acified the urine in all paraplegic patients with $\mathrm{pH}$ values over 6.2 , with oral L-Me-

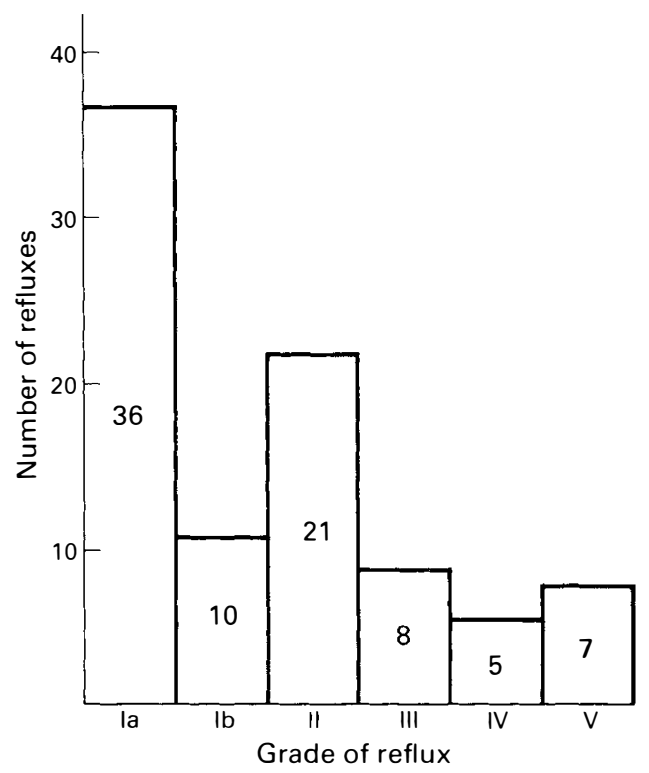

Figure 4 Reflux grades before operative treatment. thionin $(3 \times 0.5-1.0 \mathrm{~g}$ per day $)$. This has been standard practice in this department since work began there in 1981.

Preoperative urodynamic measurements demonstrated generally increased maximal voiding pressure $-106 \mathrm{~cm} \mathrm{H}_{2} \mathrm{O}$ (range 50-200), and resistance coefficient $14.7 \mathrm{~cm} \mathrm{H}{ }_{2} \mathrm{O} / \mathrm{ml} / \mathrm{sec}$ (range 5-66).

The surgical treatment was performed from 1982 to 1988. Sixty-eight patients with increased bladder outlet resistance underwent 164 surgical procedures (transurethral incision or resection of the bladder neck, transurethral resection of prostate, sphincterotomy) during 85 operations. Sixty-two operations $(73 \%)$ consisted of 2 or more surgical procedures (Table II).

All 3 female patients had a single sphincterotomy, and in one of these patients the operation was repeated 6 weeks later.

\section{Results}

Of a total number of 68 operated patients with increased bladder outlet resistance and 87 VUR, infusion urography and voiding cystourethrograms combined with urodynamic evaluation were carried out within 6 weeks to 36 months postoperatively, usually after 12-18 months, and were continued regularly every $1.5-2$ years.

The postoperative urodynamic measurements demonstrated in the main a decreased maximal voiding pressure $-72 \mathrm{~cm} \mathrm{H}_{2} \mathrm{O}$ (range 25-140), and resistance coefficient $9.3 \mathrm{~cm} \mathrm{H} \mathrm{H}_{2} \mathrm{O} / \mathrm{ml} / \mathrm{sec}$ (range 2-20).

Although the primary aim of operative treatment was to achieve balanced voiding, 62 refluxes (71\%) disappeared, $10(12 \%)$ changed for the better (for example $\mathrm{II} \rightarrow \mathrm{Ia}), 13(15 \%)$ stood unchanged and 2 $(2 \%)$ worsened. Correlation between reflux stage before treatment and results was not stated (Fig 5).

The change for the worse occurred in a 44 year old patient with bilateral VUR stage Ib 3 months after the operation, a control voiding cystourethrogram showing bilateral VUR stage II. The continuation of therapy and follow up examinations were impossible, because the patient emigrated.

In 12 patients with 13 unchanged reflux the balanced voiding has still not yet been 
Table II Bladder outlet resistance decreasing operations in spinal cord damaged patients with vesicoureteral reflux

\begin{tabular}{lr}
\hline Procedures & Total \\
\hline $\begin{array}{l}\text { Sphincterotomy, as described by } \\
\text { Madersbacher-Scott (S) }\end{array}$ & 78 \\
Transurethral incision of the blad- & 40 \\
der neck (TUIBN) by Turner-War- & \\
wick technique & \\
Transurethral resection of prostate & 35 \\
(TURPro) & \\
Transurethral resection of the blad- & \\
der neck (TURBN) & 11 \\
& 164 \\
Operations (single procedures) & \\
S & 17 \\
TURPro & 3 \\
TURBN & 2 \\
TUIBN & 1 \\
& 23 \\
Operations (combinations) & \\
S + TURPro & 23 \\
S + TUIBN & 21 \\
S + TURBN & 8 \\
S + TUIBN + TURPro & 5 \\
other & 5 \\
& 62 \\
\hline
\end{tabular}

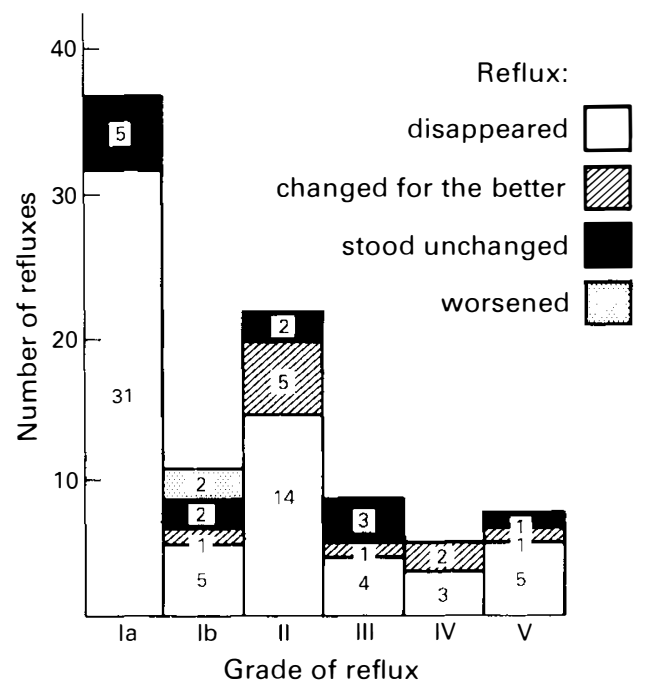

Figure 5 Reflux grades after operative treatment. achieved. Operative treatment will be repeated in 10 patients; the other 2 have broken their contact with the Paraplegic Centre.

Of the 53 VUR, 25 were also found to have a urinary tract infection after operative treatment. When the influence of effective treatment of urinary tract infections on VUR was analysed, it was found that, after bladder outlet decreasing operative procedures, $79 \%$ of VUR disappeared after successful treatment of the infection and $75 \%$ of VUR disappeared despite persisting infection.

\section{Discussion}

We studied retrospectively 68 patients after SC injury with 87 VUR. All had increased bladder outlet resistance and underwent transurethral operative treatment. Very good and good results (relief of the outflow obstruction shown by means of urodynamic studies; reflux disappeared or improved) were not dependent on reflux stage before treatment. Therefore, we assume that the grade of parenchymal scarring and ureteral pelvis and calices changes do not influence the results of treatment of secondary VUR. We may conclude that the results of operative treatment of secondary VUR depend only on the recuperative capacity of the ureterovesical junction after sufficiently decreasing the pathologically increased bladder outlet resistance. But control radiographic examinations (infusion urography) showed an unchanged grade of parenchymal scarring even 24 months after definitive disappearing of VUR (36 months postoperatively). Therefore we agree with the International Reflux Study Committee that renal scarring is permanent, despite successful surgical intervention of VUR.

In only a small number of patients was increase of incontinence observed (mostly stress incontinence after resection of the bladder neck); some other patients noticed an increase of dry intervals following micturition (in most cases after a single sphincterotomy). Nevertheless, in our study we do not consider the influence of bladder outlet resistance decreasing operations on the outcome of incontinence in spinal cord dam- 
aged patients with VUR. It should be stressed that the preservation of kidney function appears to us to be incomparably more important than continence.

No significant influence of the successful treatment of urinary tract infection on abolishing VUR after bladder outlet resistance decreasing operations was found.

\section{Conclusions}

1 In spinal cord damaged patients with vesicoureteral reflux the operative or pharmacological decrease of bladder outlet resistance is the treatment of choice.

2 The majority of bladder outlet resistance decreasing operations consist of 2 or more surgical procedures.

3 Results of the operative treatment of secondary VUR depends only on the recuperative capacity of the ureterovesical junction after decreasing pathologically increased bladder outlet resistance.

4 Successful treatment of secondary vesicoureteral reflux does not influence already existing renal parenchymal scarring.

\section{References}

1 Buzelin JM, Jurascheck F (1981) Les complications urologiques et leur traitement. In: Maury M. La Paraplegie. Flammarion, Paris, 334-366.

2 Fellows GJ, Silver JR (1976) Long-term follow-up of paraplegic patients with vesicoureteral reflux. Paraplegia 14: 130-134.

3 VanArsdalen KN, Hackler RN (1983) Transurethrostomy in spinal cord injury patients for persistent vesicoureteral reflux: 6 to 14 years follow-up. J Urol 129: 1117-1119.

4 Leriche A, Sayag JL, Archimbaud JP (1983) Le reflux dans les neurovessies acquises de l'adulte. Aspects prognostiques et therapeutiques a propos de 237 reflux chez 156 paraplegiques. Med Hyg 41: 4181-4193.

5 Burgdoerfer H, Busch R, Becker H (1984) Zeitgemaesse urologische Betreung Querschnittgelaehmter. In: Bericht ueber die Unfallmedizinische Tagung, Hauptverband der gewerblichen Berufsgenossenschaften e.V., Bonn: 303-315.

6 Stoehrer M, Palmtag H, Madersbacher H (1984) Blasenlaehmung. Sexualitaet und Blasenfunktion bei Rueckenmarkverletzten und Erkrankungen des Nervensystems. Georg Thieme Verlag, Stuttgart, New York: 84.

7 Madersbacher H, Brantley Scott F (1976) The twelve o'clock sphincterotomy: technique, indications, results. Paraplegia 13: 261-267.

8 International Reflux Study Committee (1981) Medical versus surgical treatment of primary vesicoureteral reflux: a prospective international reflux study in children. J Urol 125: 277-183. 